\title{
Debating Disciplinarity
}

\author{
Robert Post
}

I am a lawyer, and lawyers have their priors. One is that no question is innocent. Every question springs from an agenda that determines the range of acceptable answers. So if I am asked, as I have been for these remarks, "what is a discipline?" I want to know who is asking and for what purpose.

Sometimes questions of disciplinarity seek criteria for validating the "eccentric" angle of vision of a particular "intellectual" community in terms of its "methodology,"2 or "subject-matter,"3 or "curriculum,"4 or shared "purpose." Sometimes questions of disciplinarity express apprehension about the "subordinate status" of a colonized discipline, ${ }^{6}$ or about the meaning of interdisciplinarity, ${ }^{7}$ transdisciplinarity, ${ }^{8}$ or "dedisciplinar-

I am grateful for the magisterial advice of Howard Bloch and Thomas Laqueur and for the unfailing assistance of YiLing Chen-Josephson.

1. Clifford Geertz, "Blurred Genres: The Refiguration of Social Thought," in Interdisciplinarity: Essays from the Literature, ed. William H. Newell (New York, 1998), p. 228.

2. Gabriel A. Almond et al., "Political Science as a Discipline," American Political Science Review 56 (June 1962): 417. See also Roy Harvey Pearce, "American Studies as a Discipline," College English 18 (Jan. 1957): 179-86, and Frederick M. Logan, "Is There a Discipline of Art Education?” Studies in Art Education 4 (Spring 1963): 10-14.

3. Anthony Nemetz, "Religion as an Academic Discipline," Journal of Higher Education 30 (Apr. 1959): 200.

4. Paul Jay, "Beyond Discipline? Globalization and the Future of English," PMLA 116 (Jan. 2001): 44 .

5. William Randel, "English as a Discipline," College English 19 (May 1958): 361.

6. James D. Herbert, "Masterdisciplinarity and the 'Pictorial Turn," Art Bulletin 77 (Dec. 1995): 539. See J. M. Balkin, "Interdisciplinarity as Colonization," Washington and Lee Law Review 53, no. 3 (1996): 949-70.

7. See Julie Thompson Klein, Interdisciplinarity: History, Theory, and Practice (Detroit, 1989); Robert L. Scott, "Personal and Institutional Problems Encountered in Being Interdisciplinary," in Interdisciplinarity and Higher Education, ed. Joseph J. Kockelmans (University Park, Pa., 1979), pp. 306-27; and Michael McKeon, "The Origins of Interdisciplinary Studies," Eighteenth-Century Studies 28 (Autumn 1994): 17-28.

8. See Basarab Nicolescu, Manifesto of Transdisciplinarity, trans. Karen-Claire Voss 
ity." And sometimes questions of disciplinarity are meant to initiate the quest for an "indiscipline"10 that will adequately express an "antiprofessionalism" hostile to "the institutional structures by means of which the various academic disciplines establish and extend their territorial claims." ${ }^{11}$

Disciplinarity is a fact of life for every American university; its influence is everywhere and is inescapable. Debates about disciplinarity are correspondingly pervasive. In this essay I shall outline the stakes involved in three common but distinct kinds of controversies about the meaning of disciplinarity: the stakes in the first controversy are about how universities can best accomplish their research missions; the stakes in the second concern the scope of autonomy that universities may properly assert against external forces of political and social control; and the stakes in the third turn on the articulation and enactment of professional solidarity and identity. The question of disciplinarity arises in all three kinds of controversies, but the implications of the question differ in each.

Disciplinary debates cannot be analyzed without understanding how disciplines actually function in contemporary American universities. "According to the Oxford English Dictionary, 'discipline' pertained to the dis-

(Albany, N.Y., 2002), and Transdisciplinarity: Joint Problem Solving among Science, Technology, and Society, ed. Klein et al. (Basel, 2001). To transdisciplinarity, we might also add concerns with "multidisciplinarity" and "crossdisciplinarity" (Carl R. Hausman, "Introduction: Disciplinarity or Interdisciplinarity?" in Interdisciplinarity and Higher Education, p. 10).

9. Clifford Siskin, "Gender, Sublimity, Culture: Retheorizing Disciplinary Desire," Eighteenth-Century Studies 28 (Autumn 1994): 38.

10. W. J. T. Mitchell, "Interdisciplinarity and Visual Culture," Art Bulletin 77 (Dec. 1995): 541; hereafter abbreviated "I."

11. Stanley Fish, "Being Interdisciplinary Is So Very Hard to Do," Profession (1989): 15. See also Fish, Professional Correctness: Literary Studies and Political Change (Oxford, 1995).

Robert Post is the David Boies Professor of Law at the Yale Law School. He is the author of Constitutional Domains: Democracy, Community, Management (1995); coauthor, with Matthew W. Finkin, of For the Common Good: Principles of American Academic Freedom (2009); and coauthor, with K. Anthony Appiah, Judith Butler, Thomas C. Grey, and Reva Siegel, of Prejudicial Appearances: The Logic of American Antidiscrimination Law (2001). He is the editor of Censorship and Silencing: Practices of Cultural Regulation (1998) and Law and the Order of Culture (1991), and coeditor, with Michael Rogin, of Race and Representation: Affirmative Action (1998) and, with Carla Hesse, of Human Rights in Political Transitions: Gettysburg to Bosnia (1999). He is presently finishing a book tentatively entitled Knowing What We Talk About: Expertise, Democracy, and the First Amendment. 
ciple or scholar, while 'doctrine' was the property of the doctor or teacher. As a result, 'discipline' has been associated with practice or exercise and 'doctrine' with abstract theory." ${ }^{22}$ When we speak of a discipline, therefore, we speak not merely of a body of knowledge but also of a set of practices by which that knowledge is acquired, confirmed, implemented, preserved, and reproduced. ${ }^{13}$ Disciplines "mark the point at which" this knowledge and these practices "are institutionalized, or, so to speak, the word is made flesh." ${ }^{14}$

Disciplines differ in how they institutionalize knowledge. "Disciplines vary in the ways they structure themselves, establish identities, maintain boundaries, regulate and reward practitioners, manage consensus and dissent, and communicate." ${ }^{15}$ Disciplines also differ in the internal coherence of their methodology and subject matter. To invoke the authority of a discipline, however, is nevertheless to appeal to what Kant might call the regulative idea ${ }^{16}$ of a unitary and "formalized method of knowing and expressing the knowledge of a given subject-matter." ${ }^{17}$ Any literate member of the American academy fully appreciates the authority of such an appeal. And yet, of course, most of us also realize that "the notion of disciplinary unity is triply false: minimizing or denying differences that exist across the plurality of specialties grouped loosely under a single disciplinary label, undervaluing connections across specialties of separate disciplines, and discounting the frequency and impact of cross-disciplinary influences." ${ }^{18}$

Disciplines differ from professions in that disciplines refer primarily to

12. David R. Shumway and Ellen Messer-Davidow, "Disciplinarity: An Introduction," Poetics Today 12 (Summer 1991): 202. "What distinguishes disciplines from one another is the manner in which they formulate their questions, how they define the content of their domains and organize that content conceptually, and the principles of discovery and verification that constitute the ground rules for creating and testing knowledge in their fields" (Lee S. Shulman, "Disciplines of Inquiry in Education: An Overview," Educational Researcher 10 [June-July 1981]: 6).

13. "To call a field a 'discipline' is to suggest that it is not dependent on mere doctrine and that its authority does not derive from the writings of an individual or a school, but rather from generally accepted methods and truths" (Shumway and Messer-Davidow, "Disciplinarity," p. 202).

14. Steve Fuller, "Disciplinary Boundaries and the Rhetoric of the Social Sciences," Poetics Today 12 (Summer 1991): 302.

15. Klein, "A Conceptual Vocabulary of Interdisciplinary Science," in Practising Interdisciplinarity, ed. Peter Weingart and Nico Stehr (Toronto, 2000), p. 18.

16. The regulative idea of a discipline would be the "imaginary focus from which the concepts" of the discipline "seem to proceed, even though there is nothing knowable at that focus" (J. N. Findlay, Kant and the Transcendental Object: A Hermeneutic Study [Oxford, 1981], p. 241).

17. Pearce adds tellingly that "its form, to be valid and authentic, must reflect the form of its subject-matter" (Pearce, "American Studies as a Discipline," p. 181).

18. Klein, "Blurring, Cracking, and Crossing: Permeation and the Fracturing of Discipline," 
forms of knowing that are situated within universities. ${ }^{19}$ Disciplinarity involves the education, certification, hiring, and promotion of university professors. ${ }^{20}$ American universities are now chiefly organized through departments, which "have become the principal bases of power within universities." ${ }^{21}$ Universities hire, promote, and reward faculty chiefly through departments..$^{22}$ It is significant, therefore, that "most departments have been oriented toward and identified in terms of specific disciplines" ("DD," p. 896).

in Knowledges: Historical and Critical Studies in Disciplinarity, ed. Messer-Davidow, Shumway, and David J. Sylvan (Charlottesville, Va., 1993), p. 190.

Close scrutiny of epistemological structures reveals that most modern disciplines embrace a wide range of subspecialties with different features. Unidisciplinary competence is a myth, because the degree of specialization and the volume of information that fall within the boundaries of a named academic discipline are larger than any single individual can master. ... Consequently meetings of such massive professional organizations as the Modern Language Association, the American Anthropological Association, and the American Historical Association are actually congeries of specialties, some isolated from each other, others closely related. [Ibid., pp. 188-89]

"Disciplines are shotgun marriages, either of specialities ... or of multiple and often conflicting purposes, and are kept together by the reality of the market and the value of the protection of the market that has been created by employment requirements and expectations" (Stephen Turner, "What Are Disciplines? And How Is Interdisciplinarity Different?" in Practising Interdisciplinarity, p. 55).

19. "Common sense identifies the term discipline with the content of an academic enterprise" (Shumway, "Disciplinarity, Corporatization, and the Crisis: A Dystopian Narrative," Journal of the Midwest Modern Language Association 32 [Winter-Spring 1999]: 2).

20. So much so that Stephen Turner has defined disciplines as the kind of "collectivities that include a large proportion of persons holding degrees with the same differentiating specialization name, which are organized in part into degree-granting units that in part give degree-granting positions and powers to persons holding these degrees; persons holding degrees of this particular specialized kind are employed in positions that give degree-granting powers to them, such that there is an actual exchange of students between different degreegranting institutions offering degrees in what is understood to be the same specialization" (Turner, "What Are Disciplines?" p. 47).

21. Robert Straus, "Departments and Disciplines: Stasis and Change," Science, 30 Nov. 1973, p. 896; hereafter abbreviated "DD." "The department remains the basic organizational unit" (Thomas Bender, "Politics, Intellect, and the American University, 1945-1995," in American Academic Culture in Transformation: Fifty Years, Four Disciplines, ed. Bender and Carl E. Schorske [Princeton, N.J., 1997], p. 46). Thomas Reese notes that in German universities, by contrast, "the major social unit ... was the individual chair and its associated structures— the seminars and the research institute or laboratory. Each unit supported an apprenticeship grouping, which was composed of advanced students and assistants but not other chairholders" (Thomas F. Reese, "Mapping Interdisciplinarity," Art Bulletin 77 [Dec. 1995]: 545; hereafter abbreviated "MI").

22. "As political units, departments compete with each other for such sources of power as funds, space, curriculum prominence, and number of faculty positions; they are also concerned with distributing duties and responsibilities and with allocating space, equipment, personal assistance, salary increments, promotions, tenure, and other rewards among their faculty members" ("DD," p. 896). 
Questions of disciplinarity are for this reason frequently entangled with questions of departmental politics. Fields that seek to transcend departments and disciplines, like women's studies, have found themselves "disciplined by disciplines, not only for [their] sources of faculty, but also as a corollary, for [their] core intellectual frameworks and paradigms." ${ }^{23}$

Although the institutionalization of disciplines and the intersubjective character of disciplinary norms make disciplines resistant to alteration, ${ }^{24}$ disciplines nevertheless grow and evolve. The practices of disciplines are continuously adjusting to the changing interests of disciplinary practitioners and to the emergent demands placed on disciplines by exogenous forces like universities and society at large. ${ }^{25}$ Disciplines also evolve in response to the unfolding of their own internal logic. They sometimes splinter and sometimes merge. Disciplines can be born and they can die.

In America today disciplines possess independent disciplinary institutions that are organized on a national scale. Disciplinary organizations like the American Historical Association, the American Political Science Association, and the Modern Language Association typically serve to socialize professors into disciplinary research agendas and disciplinary criteria of quality. ${ }^{26}$ Disciplinary organizations tend to standardize departmental instruction, training, and research and in this way to facilitate professorial movement between universities. ${ }^{27}$

Disciplinary publications are important gatekeepers of disciplinary norms. Who publishes in which journal or with which press is an important indicator of scholarly influence and merit. Virtually all universities use publications as criteria for institutional hiring and advancement. "The

23. Judith A. Allen and Sally L. Kitch, "Disciplined by Disciplines? The Need for an Interdisciplinary Research Mission in Women's Studies," Feminist Studies 24 (Summer 1998): 293. "Even in the half of all U.S. universities and colleges with joint women's studies faculty appointments, the disciplinary department is generally the site of tenure and promotion" (ibid., p. 294). For other examples, see Theodore Hershberg, "The Fragmentation of Knowledge and Practice: University, Private Sector, and Public Sector Perspectives," in Interdisciplinarity, p. 198.

24. Joseph J. Kockelmans defines a discipline as "a branch of learning or a field of study characterized by a body of intersubjectively acceptable knowledge, pertaining to a well-defined realm of entities, systematically established on the basis of generally accepted principles with the help of methodical rules or procedures; e.g., mathematics, chemistry, history" (Kockelmans, "Why Interdisciplinarity?" in Interdisciplinarity and Higher Education, p. 127).

25. See Stephen Toulmin, The Collective Use and Evolution of Concepts, vol. 1 of Human Understanding (Princeton, N.J., 1972), p. 154.

26. See ibid., p. 274. See also Maureen Daly Goggin, "Composing a Discipline: The Role of Scholarly Journals in the Disciplinary Emergence of Rhetoric and Composition since 1950," Rhetoric Review 15 (Spring 1997): 322-48.

27. Reese argues that "although academics belong to several communities (discipline, academic profession, university enterprise, and national academic system), the culture of the discipline, especially in the United States, generally has the strongest bonding power because it is often easier to leave the institution than the discipline" ("MI," p. 544). 
institutional structure of scholarly journals serves to reinforce disciplinary hierarchies: at the lowest level, the evaluator, reader, or reviewer is implicitly considered to be qualified to make judgments about a contribution at a level above that of the contributor himself. From there the hierarchy extends to the editorship, and the selection processes for filling the intervening positions evidently reinforce the hierarchizing and orthodoxy of the discipline in question." ${ }^{28}$

Disciplines and universities are thus symbiotically interconnected. Disciplinary institutions and networks entrench the norms by which universities hire and evaluate professors, but universities hire the faculty who populate disciplinary institutions and who perpetuate disciplinary knowledge and practices through departments.

This sketch of the contemporary status of disciplines suggests the first and probably most common class of disciplinary debates. We can expect controversy whenever the institutional and normative structure of a discipline conflicts with the functional mission of universities.

Modern American universities serve many functions, but undoubtedly the two most important are higher education and the production of knowledge. With respect to the first of these functions, undergraduate education may be more or less connected to disciplinary practices depending upon underlying pedagogical goals. ${ }^{29}$ Most universities prefer to conduct undergraduate education through the vehicle of disciplinary training, however rudimentary. But to the extent that undergraduate education is conceived in generalist terms that emphasize the inculcation of character and abstract mental competences, universities must invent institutional structures other than disciplinary departments to fulfill this function. Because disciplines are oriented toward the acquisition of knowledge, rather

28. Wolfram W. Swoboda, "Disciplines and Interdisciplinarity: A Historical Perspective," in Interdisciplinarity in Higher Education, pp. 78-79. "Gatekeepers, by virtue of their position as evaluators (editors of journals, referees of manuscripts, reviewers of grant proposals), decide which work will be presented in public forums and which will languish in obscurity. Upon cumulative decisions of this kind depend the professional and epistemological selections - who gets tenured and promoted, which knowledges are advanced and disseminated-that constitute a disciplinary repertoire" (Messer-Davidow, review of Academic Tribes and Territories: Intellectual Enquiry and the Cultures of Disciplines by Tony Becher, Interdisciplinarity: History, Theory, and Practice by Klein, Creative Marginality: Innovation at the Intersections of the Social Sciences by Mattei Dogan and Robert Pahre, Transforming Knowledge by Elizabeth Minnich, and Feminist Knowledge: Critique and Construct by Sneja Gunew, Signs 17 [Spring 1992]: 679).

29. The connection between disciplinarity and graduate education is much tighter, at least to the extent that graduate education is dedicated to producing professors who will be hired by university departments that are identified with disciplinary practices. As Reese puts it, "to guarantee respect and secure jobs, there are rigorous methodological initiations in graduate training followed by admission to guildlike disciplinary and departmental structures" ("MI," p. 544). 
than the education of undergraduates, the invention of these structures needn't strain commitments to disciplinarity. Universities can offer courses in composition without undue concern about whether the teaching of prose writing is itself a discipline.

Matters are quite otherwise, however, when disciplinary practices conflict with the imperative of universities to produce knowledge. Disciplines in large part exist to produce knowledge, and when universities regard disciplines as having failed in this objective, tension is certain to ensue..$^{30}$ This tension is most obviously recurrent in the sciences, which "tend to work on problems not in disciplines." ${ }^{11}$ To the extent that research imperatives arising within universities are oriented toward problems that resist solution within the parameters of traditional disciplinary perspectives, universities possess incentives to engage in interdisciplinary approaches, ${ }^{32}$ as can be seen in the recent growth of "environmental science." This "interdisciplinarity may best be described as a result of opportunism in knowledge production." ${ }_{33}$

If research problems resisting disciplinary solutions are sufficiently significant and enduring and if they can be profitably addressed through the development of genuinely new practices of understanding, the problems can generate new disciplines, as may be happening now in the fields of artificial intelligence or cognitive science. ${ }^{34}$ In such contexts, the question, What is a discipline? is directed to the creation of knowledge practices that can solve relevant research problems and to the institutionalization of these practices in the training of graduate students, the hiring of professors, the organization of university departments, the establishment of extramural disciplinary organizations, the creation of scholarly journals, and so on. As the research agenda of universities evolves, and as the most effective response to this changing agenda requires the transformation of knowledge practices, we can expect complementary changes in the internal organization of universities and in the composition of external disciplinary institutions.

Generally speaking, sciences proceed on the basis of what Jürgen Habermas, in his early work, called the "knowledge-constitutive interest" of instru-

30. For a good discussion of how universities shape their disciplinary structure in order to meet exogenous demands for knowledge, in particular from industrialization, see Swoboda, "Disciplines and Interdisciplinarity."

31. Klein, "A Conceptual Vocabulary of Interdisciplinary Science,” p. 13.

32. For a good discussion of this process, see Klein, "Blurring, Cracking, and Crossing."

33. Weingart, "Interdisciplinarity: The Paradoxical Discourse," in Practising Interdisciplinarity, pp. 38, 39. See Hershberg, "The Fragmentation of Knowledge and Practice," p. 207.

34. See Klein, “A Conceptual Vocabulary of Interdisciplinary Science,” p. 19. 
mental reason. ${ }^{35}$ Science seeks pragmatically to predict and control the world. The humanities, by contrast, typically proceed on the basis of the quite different interest of "maintaining the intersubjectivity of mutual understanding in ordinary-language communication and in action according to common norms. ${ }^{36}$ For this reason the humanities do not solve problems in the same way as the sciences. Scientific knowledge can be tested against the sharp and bounded imperatives of prediction and control, but the humanities must instead gratify needs for human meaning, understanding, and cooperation that are perennially diffuse and unsettled. What counts as knowledge is thus far more controversial in the humanities than in the sciences.

Nevertheless the humanities, just like the sciences, can face research agendas that seem to render traditional disciplines unresponsive, and in such circumstances the definition of humanities disciplines will come under strain. If the sciences must organize themselves adequately to react to technological innovations like the computer, so the humanities must organize themselves adequately to react to newly emerging needs to comprehend issues like race or gender, where our desire for "mutual understanding" has for whatever reason grown particularly urgent. In the sciences this stress has produced the (more or less) orderly emergence of new disciplines, ${ }^{37}$ but, strangely enough, this has not been true for the humanities.

Some literary scholars, for example, sought to respond to the imperative to contextualize cultural texts by changing the "function" of the "discipline" from "teaching literature, in the conservative Arnoldian sense of 'the best that was thought and said" to "engaging students in understanding how our disciplines and culture, as well as our interpretations, are themselves texts that have been constituted and that have the power and authority of texts." The upshot was to produce a new field, now called

35. Jürgen Habermas, Knowledge and Human Interests, trans. Jeremy J. Shapiro (Boston, 1971), p. 135; see esp. pp. 113-40.

36. Ibid., p. 176; see esp. pp. 140-86.

37. See, for example, Hausman, "Disciplinarity or Interdisciplinarity?” p. 8, and Alberto Cambrosio and Peter Keating, "The Disciplinary Stake: The Case of Chronobiology," Social Studies of Science 13 (Aug. 1983): 323-53.

Experimental biology has come to be seen as the most powerful force in the modern reconception of the nature of life and in the radical transformation of medical practice. This transformation had diverse sources, but none was more telling than the attempt to subject issues in late-nineteenth century evolutionary and developmental biology to experimental scrutiny. That general research program led to the emergence of new disciplines such as embryology, cytology, endocrinology, the reproductive sciences, and genetics, which rapidly took on lives of their own, independent of evolutionary debates, and produced a wide range of conceptual and utilitarian triumphs. [Daniel J. Kevles and Gerald L. Geison, "The Experimental Life Sciences in the Twentieth Century," Osiris 10, 2d ser. (1995): 97] 
cultural studies, which sought to transform "literary study as a discipline" into "a community where anthropological field work can be done." ${ }^{38}$ In essence, humanities scholars focused on a new subject matter, but they borrowed existing methodological practices from other disciplines like anthropology. It thus remains a real question whether the emerging field of cultural studies is in fact a new discipline or instead is an amalgam of existing disciplines. ${ }^{39} \mathrm{~A}$ similar question bedevils other newly coined areas, like women's studies or ethnic studies. ${ }^{40}$

It is a genuine puzzle why the humanities cannot seem easily to transcend traditional disciplinary methods like the textual exegesis of literary criticism, the analytics of philosophy, the narratives of history, or the cultural hermeneutics of anthropology. Although "the overblown and oversold status of the established disciplines in the field of human and social studies" has been attacked time and again, ${ }^{41}$ it has in fact proved surprisingly difficult to generate stable and enduring new disciplinary formations

38. Jeffrey M. Peck, "Advanced Literary Study as Cultural Study: A Redefinition of the Discipline," Profession (1985): 51, 53.

39. See, for example, Patrizia Lombardo, "Cultural Studies and Interdisciplinarity," Critical Quarterly 34 (Autumn 1992): 3-10. "Cultural studies ... has emerged in the American academy as a counter-hegemonic 'marketing strategy' for a diverse array of knowledge projects clustered around politics, identity, media, and critical theory.... Cultural studies is an academic movement" ("I," p. 541). "Cultural studies is not a discipline; it has no organization, no annual meeting, and very few departments. Most of the departments that do exist are renamed versions of other disciplines. Most of the practitioners ... are in some other discipline: communications, literature, film studies, anthropology. For the most part, cultural studies is not an institutional space; it is an interdisciplinary one, an intellectual one" (Ken Wissoker, "Negotiating a Passage between Disciplinary Borders," Chronicle of Higher Education, 14 Apr. 2000, p. B5). "One finds few departments or programs where faculty appointments can be made directly in cultural studies. Faculty members who do cultural studies are thus required to pass muster both in departmentally based disciplines and in their freely chosen interdisciplinarity. ... For all the intellectual excitement generated by the cultural studies movement, its material base seems pretty flimsy compared with that of established departments" (Renato Rosaldo, "Whose Cultural Studies?" American Anthropologist 96 [Sept. 1994]: 525). On "transdisciplinary academic journals" spawned by the turn toward cultural studies, see David A. Hollinger, "The Disciplines and the Identity Debates, 1970-1995," in American Academic Culture in Transformation, pp. 353-56.

40. See Allen and Kitch, "Disciplined by Disciplines?" Alice Kessler-Harris and Amy Swerdlow, although arguing that "the conventional wisdom these days, held by both friend and foe, is that women's studies has made it as an academic discipline," also concede that women's studies programs "depend on the goodwill of traditional academic departments" and that the graduate students in such programs "often find themselves choosing research topics that will win them tenure in their more-traditional disciplines" (Alice Kessler-Harris and Amy Swerdlow, "Pride and Paradox: Despite Success, Women's Studies Faces an Uncertain Future," Chronicle of Higher Education, 26 Apr. 1996, p. A64). On ethnic studies, see Marjorie Garber, "Coveting Your Neighbor's Discipline," Chronicle of Higher Education, 12 Jan. 2001, p. B9; "I," p. 542; and Vincent B. Leitch, "Postmodern Interdisciplinarity," Profession (2000): 124-31.

41. Benjamin I. Schwartz, "Presidential Address: Area Studies as a Critical Discipline," Journal of Asian Studies 40 (Nov. 1980): 17. 
in the humanities. ${ }^{42}$ The proliferation of new disciplines in the sciences depends in part on the fact that new domains of knowledge often require new techniques of knowledge acquisition, so methodology necessarily changes in step with the subject matter to be studied. In the humanities, by contrast, new domains of knowledge are quite regularly assimilated to traditional disciplinary methods. The persistence of these methods seems to reflect deeply entrenched modalities through which "the intersubjectivity of mutual understanding in ordinary-language communication" can be established.

In truth the humanities in recent years have evidenced a troubled relationship to disciplinarity. Humanities scholarship seems to embrace an enduring tendency to reject the "technological expertise" of a "socially marginal professionalism" in favor of "maintaining a general humanistic responsibility for the culture as a whole." 43 Questions of expertise make humanities scholars "anxious," 44 in part because the authority of expertise

42. Vincent Leitch argues, on the basis of "three decades of interdisciplinary work of various kinds - in a large humanities department, in a small honors great-books program, in a medium-sized graduate comparative literature program, in a small doctoral program in philosophy and literature, and in a small graduate concentration in theory and cultural studies," that "interdisciplinary work supports or modifies but does not transform - that is, change-existing disciplines. ... The origin and end of interdisciplines is the discipline" (Leitch, "Postmodern Interdisciplinarity," pp. 126, 125-26). The emerging field of film studies may be an exception to this generalization; see "I," p. 541.

43. Terry Eagleton, The Function of Criticism: From "The Spectator" to Post-Structuralism (London, 1984), pp. 56, 69, 56; hereafter abbreviated FC. On the contrast between literary criticism as "merely a discipline" and literary criticism "as the site of cultural and moral pedagogy par excellence," see S. P. Mohanty, "Radical Teaching, Radical Theory: The Ambiguous Politics of Meaning," in Theory in the Classroom, ed. Cary Nelson (Urbana, Ill., 1986), p. 149. For a good discussion, see Catherine Gallagher, "The History of Literary Criticism," in American Academic Culture in Transformation, pp. 151-71.

44. Jonathan Brody Kramnick, "Literary Criticism among the Disciplines," EighteenthCentury Studies 35 (Spring 2002): 356. Kramnick identifies two sources for the "so-called crisis of literary study." The first is the "relation between criticism and its public." The second is the disciplinary issue of "method, object or knowledge," which is to say the question of "what is the object of literary study today and where is its place in the division of knowledge" (ibid., p. 357).

Denial and disavowal are prominent features of graduate programs in the humanities but perhaps especially so in English, where there is an institutionalized reluctance to admit that undertaking a $\mathrm{PhD}$ in the field constitutes entering a professional arena with rules, guidelines, and protocols that may remain unarticulated yet exert an all-powerful force on the discipline. ... Professionalization has only recently been acknowledged as the underpinning of the profession of English at the faculty level, since for many the teaching of English in the academy still retains a whiff of lofty amateurism or a clubby kind of apprenticeship in literary appreciation. ... The conservative version of this antipathy is that professionalization is crude and destructive and that professionalized students are upstarts. The ostensibly progressive wing explains its dislike by analogy to an industrial speedup of otherwise leisurely graduate study. Some find early specialization a threat to graduate education. ... Neither form of dislike for professionalization faces the fact that for graduate students to reproduce 
contracts the sphere of potential political influence. ${ }^{45}$ Politics, as Hannah Arendt reminds us, concerns belief, and "every claim in the sphere of human affairs to an absolute truth, whose validity needs no support from the side of opinion, strikes at the very roots of all politics and all governments." ${ }^{66}$ Politics is for this reason hostile to the prerogatives of disciplinary authority or professionalism. ${ }^{47}$ In the "public realm" there is only persuasion, one citizen to another (FC, p. 65).

That is perhaps why humanities scholars who desire to open "intellectual discussion out upon a public sphere" ${ }^{48}$ are also suspicious of the mantle of professionalism and often nostalgically reflect back on the stance of a "sage's 'amateur' outlook," when criticism could communicate a "message about the shape and destiny of a whole culture" (FC, pp. 65, 107).49 But because this stance is in fundamental tension with the entire disciplinary apparatus by which humanities scholars are trained, hired, and evaluated, there is also a natural reluctance to abandon not only the many years of professional apprenticeship but also the prestige of expert authority. As a

the profession, they must be inducted into it as professionals. [Jennifer Wicke, "I Profess:

Another View of Professionalization," Profession (2001): 52-53]

45. "The problem of the Victorian man of letters is one which has never ceased to dog the English critical institution, and is indeed quite unresolved even today: either criticism strives to justify itself at the bar of public opinion by maintaining a general humanistic responsibility for the culture as a whole, the amateurism of which will prove increasingly incapacitating as bourgeois society develops; or it converts itself into a species of technological expertise, thereby establishing its professional legitimacy at the cost of renouncing any wider social relevance" (FC, pp. 56-57).

46. Hannah Arendt, "Truth and Politics," Between Past and Future: Eight Exercises in Political Thought (New York, 1968), p. 233.

47. "Seen from the viewpoint of politics, truth has a despotic character." "The story of the conflict between truth and politics is an old and complicated one. . . Throughout history, the truth-seekers and truthtellers have been aware of the risks of their business; as long as they did not interfere with the course of the world, they were covered with ridicule, but he who forced his fellow-citizens to take him seriously by trying to set them free from falsehood and illusion was in danger of his life: 'If they could lay hands on [such a] man . . . they would kill him,' Plato says in the last sentence of the cave allegory" (ibid., pp. 241, 229).

48. Michael Ryan, "Deconstruction and Radical Teaching," in The Pedagogical Imperative: Teaching as a Literary Genre, ed. Barbara Johnson (New Haven, Conn., 1982), p. 46. See Scott Heller, "Humanists Seek to Regain Their Public Voice," Chronicle of Higher Education, 7 Apr. 1993, pp. A6-A7, A12-A13.

49. "Within academic English, the conflict between 'amateur' and 'professional' was to continue, transposed into a quarrel between 'criticism' and 'scholarship': academic literary scholarship develops apace from the Victorian period onwards as a technical specialism, while academic criticism retains some nebulous preoccupation with 'life' as well as 'letters"' (FC, pp. 65-66). In his fine discussion of Raymond Williams, Eagleton modifies the idea of the amateur to that of an "isolated, dissentient sage" who aspires (but fails) to cross "the frontiers between the academic institution and political society" (FC, pp. 114, 115). 
consequence there is a complementary and recurring tendency to claim for the humanities a deep expertise after all.

This expertise is often formulated in a very special way that seems designed simultaneously to embrace and to repudiate disciplinarity. The humanities are said to be "disciplines of the imagination," the repository of a "learning that disturbs and disrupts ... that cannot be relied on for ulterior purposes and yet is wholly necessary for keeping open the options of being human, that cannot be defended on the grounds of what it is good for because no one can know what it is good for until it has been explored, examined, and weighed in each generation." 50

This formulation of disciplinary expertise is internally unstable. Every discipline must at a minimum be faithful to its own methods and techniques. ${ }^{51}$ If the humanities are in fact disciplines, they cannot be disruptive in ways that undermine the knowledge practices by which their own disciplinarity is defined. This point is not trivial. As disciplines, the humanities must establish knowledge practices that create a normal science capable of reproduction and replication in university departments throughout the country..$^{52}$ They must establish knowledge practices that yield criteria that can be used to hire, evaluate, and promote faculty in university departments and to assess the value of disciplinary work in the proceedings of disciplinary organizations and publications. Humanities scholarship cannot subvert these practices without repudiating its own disciplinarity. ${ }^{53}$

Insofar as humanities scholarship is disciplinary, therefore, it cannot be inherently "subversive" or "intrinsically revolutionary" ("SC," p. 18). To imagine humanities scholarship as promiscuously unsettling is to endow it with a form of authority that is more like that of art than like that of a discipline. Artistic authority can be inherently subversive and intrinsically revolutionary because artistic success does not appear to depend upon either reproducible methodological competence or the approval of estab-

50. Jeffrey L. Sammons, "Squaring the Circle: Observations on Core Curriculum and the Plight of the Humanities," Profession (1986): 18, 20; hereafter abbreviated "SC."

51. To define the humanities in terms of "a refusal of obedience" ("SC," p. 18) is to define them in a way that contradicts the root concept of a discipline, which, as the OED instructs us, is "the orderly conduct and action which result from training" (Oxford English Dictionary, 2d ed., s.v. "discipline").

52. See Roger B. M. Cotterrell, "Law and Sociology: Notes on the Constitution and Confrontations of Disciplines," Journal of Law and Society 13 (Spring 1986): 9-34.

53. Of course, humanities scholars can and do debate the substance of these practices. See, for example, Judith Butler, "Academic Norms, Contemporary Challenges: A Reply to Robert Post on Academic Freedom," in Academic Freedom after September 11, ed. Beshara Doumani (New York, 2006), pp. 117-29. That is quite different, however, from conceptualizing humanities scholarship as a form of charismatic engagement that altogether transcends the enabling structure of disciplinary norms. 
lished organizations like universities. ${ }^{54}$ Artistic authority is also experienced as universal because art purports to speak to all persons in the public realm about all aspects of human experience. In these respects artistic authority seems to be the implicit model for those who would conceive humanities scholarship as an intrinsically revolutionary effort to preserve the "options of being human." Certainly the contemporary tendency to conceptualize critics as artists in their own right is strong evidence in support of this hypothesis. 55

At the heart of this ongoing debate about the status of the humanities is the question of whether the authority of humanities scholarship is to be regarded as disciplinary or instead as charismatic, like artistic authority. Those in the humanities who question professionalism display a strong attraction to charismatic authority. W. J. T. Mitchell accurately characterizes charismatic authority as dependent on a form "of 'indiscipline,' of turbulence or incoherence at the inner and outer boundaries of disciplines. If a discipline is a way of insuring the continuity of a set of collective practices (technical, social, professional, etc.), 'indiscipline' is a moment of breakage or rupture, when the continuity is broken and the practice comes into question. To be sure, this moment of rupture can itself become routinized, as the rapid transformation of deconstruction from an 'event' into a 'method of interpretation' demonstrates" ("I," p. 541). Mitchell frankly avows his attachment to the "'anarchist' moment" of indiscipline, which he explicitly contrasts to less interesting disciplinary work that derives from the mastery and deployment of routinized procedures and techniques ("I," p. 541).

Of course the value of scholarship, ceteris paribus, depends upon the "wisdom" that an author can bring "to bear on the subject he is treating," whether or not "this wisdom derives from the 'methodology' of his discipline." ${ }_{56}$ And of course great masters of a discipline can be charismatic by virtue of their remarkable talent. But the tendency of humanities scholars to disparage scholarship that displays nothing more than disciplinary accomplishment is nevertheless striking. Physicists do not dismiss scholarship that is accomplished within the normal and routinized standards of their discipline. This is because physicists are confident that the ordinary application of their discipline creates useful and significant knowledge, and they are comfortable affirming the authority of that knowledge. The

54. The assertion is qualified because I am agnostic about how artistic authority is truly grounded. See, for example, James F. English, The Economy of Prestige: Prizes, Awards, and the Circulation of Cultural Value (Cambridge, Mass., 2005).

55. See, for example, Patrick Parrinder, Authors and Authority: English and American Criticism, 1750-199o (New York, 1991), pp. 285, 302-3.

56. Schwartz, "The Fetish of the 'Disciplines," Journal of Asian Studies 23 (Aug. 1964): 537. 
disposition of humanists to belittle merely disciplinary scholarship suggests an underlying worry that the humanities do not create useful and significant knowledge. ${ }^{57}$ This worry might well stimulate a compensatory desire to emulate the charismatic authority of the great productions of the human spirit that humanists typically study.

The question of whether humanities scholarship should invoke disciplinary or charismatic authority has a number of implications. One concerns the status of the thousands of ordinary humanities scholars who teach in universities throughout the country. It is simply implausible to imagine that these scholars, who mostly perform what may be called normal science, can be invested with charismatic authority. If their work is to carry authority, therefore, it must be by virtue of its disciplinarity. To belittle humanities disciplines is to strip significance from the work of the vast majority of humanities professors.

A second and less obvious implication concerns the independence that universities may properly claim against external forces that seek to control the agenda of humanities scholarship and teaching. It is commonly acknowledged that much contemporary scholarship in the humanities "seems to flow naturally from the imperatives of left culturalist theory, that is, from deconstruction, Marxism, feminism, the radical version of neopragmatism, and the new historicism. ${ }^{58}$ In the public realm these perspectives have been ruthlessly attacked by a conservative mobilization that for a time had seized control of all three branches of the federal government. Higher education has been a persistent target for coordinated assault on the ground that, according to David Horowitz, "political radicals [have taken] over academic departments." 59 The assault has been aimed squarely at humanities departments.

Universities, like all social institutions, are vulnerable to political direction and regulation. Traditionally, universities have resisted such control on the ground of academic freedom, which safeguards "freedom of inquiry and research" and "freedom of teaching within the university or college." 60

57. See Kramnick, "Literary Criticism among the Disciplines.” Edward Said has claimed there is an embrace of "amateurism" as distinct from "professionalization" in part because "'expertise' in the end has rather little, strictly speaking, to do with knowledge" (Edward W. Said, Representations of the Intellectual [New York, 1994], pp. 82, 74, 79).

58. Fish, "Being Interdisciplinary Is So Very Hard to Do," p. 15. See “I," p. 542; "MI," p. 548; and Garber, "Coveting Your Neighbor's Discipline," p. B9.

59. Neal SenGupta, "Horowitz Stirs up Crowd in Page," Duke Chronicle, 8 Mar. 2006, www .dukechronicle.com/home/index.cfm? event = displayArticlePrinterFriendly\&uStory_id=8aac2013b85b-4fi6-9739-0337a9788a57

60. American Association of University Professors (AAUP), "1915 Declaration of Principles on Academic Freedom and Academic Tenure," AAUP Bulletin 1 (Dec. 1915); rpt. in AAUP, Policy Documents and Report (Washington D.C., 2001), p. 292; hereafter abbreviated “DP.” 
In essence, academic freedom marks the independence that universities may claim from external forces like those that presently seek to intimidate and coerce humanities scholars.

Academic freedom represents a bargain that universities have struck with the public; universities produce knowledge in return for the freedom prerequisite for the production of that knowledge. ${ }^{61}$ Academic freedom presupposes that faculty are experts in the production of knowledge and that faculty freedom of research and publication must be protected because "the first condition of progress is complete and unlimited freedom to pursue inquiry and publish its results" (“DP," p. 295)..$_{2}^{2}$ Academic freedom does not imply "that individual teachers should be exempt from all restraints as to the matter or manner of their utterances, either within or without the university" ("DP," p. 300). It implies instead that the "liberty of the scholar within the university to set forth his conclusions, be they what they may, is conditioned by their being conclusions gained by a scholar's method and held in a scholar's spirit; that is to say, they must be the fruits of competent and patient and sincere inquiry" ("DP," p. 298). ${ }^{63}$ Academic freedom safeguards "not the absolute freedom of utterance of the individual scholar, but the absolute freedom of thought, of inquiry, of discussion and of teaching, of the academic profession" ("DP," p. 300). This freedom is protected because the unhindered exercise of professional expertise is deemed a necessary precondition for the production of knowledge within universities.

The question of whether humanities scholarship should depend upon disciplinary or charismatic authority has important implications for the

61. For a full discussion, see Robert Post, "The Structure of Academic Freedom," in Academic Freedom after September 11, pp. 61-106, and Matthew W. Finkin and Post, For the Common Good: Principles of American Academic Freedom (New Haven, Conn., 2009), pp. 29-45.

62. In the words of Arthur Lovejoy, one of the draftsmen of the "Declaration of Principles on Academic Freedom and Academic Tenure":

The function of seeking new truths will sometimes mean ... the undermining of widely or generally accepted beliefs. It is rendered impossible if the work of the investigator is shackled by the requirement that his conclusions shall never seriously deviate either from generally accepted beliefs or from those accepted by the persons, private or official, through whom society provides the means for the maintenance of universities... Academic freedom is, then, a prerequisite condition to the proper prosecution, in an organized and adequately endowed manner, of scientific inquiry. [Arthur O. Lovejoy, "Academic Freedom," in Encyclopedia of the Social Sciences, ed. Edwin R. A. Seligman and Alvin Johnson, 15 vols. (New York, 1930-37), 1:384-85]

63. This is why universities routinely judge and evaluate faculty based upon the quality of their work. If the work is sufficiently poor, faculty will be denied tenure and advancement. This practice of judgment is inconsistent with any understanding of academic freedom that enshrines a right to individual expression. 
application of academic freedom. To the extent that humanities scholarship disclaims disciplinary authority, to the extent that it abandons claims for the expert production of knowledge, it repudiates the traditional justification for academic freedom. It thus opens itself up to the attack that right-wing activist Horowitz recently leveled at Duke humanities scholars: "we hire these professors and give them lifetime jobs because they are experts.... However, these people are not experts." ${ }^{64}$

If humanities scholarship does not produce expert knowledge, if it is merely a vehicle for sage amateurs to advise their fellow citizens, humanities scholarship places itself outside the protective shield of academic freedom and renders itself vulnerable to the ordinary political recrimination and reprisal that envelops all citizens who enter the public realm. ${ }^{65}$ Debates about the disciplinarity of humanities scholarship thus carry rather large stakes for the autonomy that humanities scholarship can claim from external political control.

A roughly similar point can be made in the context of classroom teaching. Throughout the country, conservative groups like Students for Academic Freedom, ${ }^{66}$ the American Council of Trustees and Alumni (ACTA), ${ }^{67}$ and NoIndoctrination.org ${ }^{68}$ have mobilized in order to attack what they regard as a "growing political intolerance and abuse of academic freedom on campus." 69 They especially object to the use of college classrooms for the "indoctrination" 70 of "politically correct ideas." ${ }^{11}$ They argue

64. Quoted in SenGupta, "Horowitz Stirs up Crowd in Page." "Horowitz attacked specific Trinity College of Arts and Sciences academic programs and departments as examples of 'political parties,' including the Women's Studies Program, Program of Literature, the Department of African and African-American Literature and the cultural anthropology department. 'Large parts of this University have been subverted by radical, leftist recruiting,' Horowitz said" (ibid.). The genre is of course widespread. See, for example, John R. Searle, "The Storm over the University," review of Tenured Radicals: How Politics Has Corrupted Our Higher Education by Roger Kimball, The Politics of Liberal Education, ed. Darryl L. Gless and Barbara Herrnstein Smith, and The Voice of Liberal Learning: Michael Oakeshott on Education, ed. Timothy Fuller, New York Review of Books, 6 Dec. 1990, pp. 34-42.

65. Citizens who are not professional academics do not enjoy the prerogative of academic freedom and are not protected against reprisals by private employers for unpopular public speech. See Post, "The Structure of Academic Freedom," pp. 62 n. 10, 73-74, 85. Even faculty are not protected against reprisals for unpopular public speech insofar as reprisals are directed at their administrative, rather than scholarly, responsibilities. See Jeffries v. Harleston, 52 F.3d 9 (2d Cir. 1995).

66. See www.studentsforacademicfreedom.org/

67. See www.goacta.org/about/mission-and-history.cfm

68. See www.noindoctrination.org/

69. ACTA, "Academic Freedom," www.goacta.org/issues/academic-freedom.cfm?CFID= 167605\&CFTOKEN = 8735e6d1837dae87-DC026583-9176-4254-D6o9B70030EBFEE6

70. Students for Academic Freedom, “Academic Bill of Rights," studentsforacademicfreedom .org/abor.html

71. ACTA, “Academic Freedom." "Students report feeling intimidated by professors and 
that "liberal arts faculties at most universities are politically and philosophically one-sided, while partisan propagandizing often intrudes into classroom discourse.... Faculty bias is reflected in the curriculum of courses available, in the manner in which they are taught, in readings assigned for classroom study, and in discussions only open to one side of a debate."72

Principles of academic freedom are the primary defense against these efforts to intimidate and censor classroom teaching. These principles protect the freedom of professors to educate their students in the attainment of "a mature independence of mind." ${ }^{\text {"3 }}$ But these principles also condemn the abuse of classroom authority to indoctrinate students in ways that are without legitimate pedagogical justification. ${ }^{74}$ Academic freedom defends the autonomy of classroom teaching only insofar as such teaching constitutes education rather than indoctrination. Disciplinary standards offer the most cogent and secure way to distinguish education from indoctrination..$^{75}$

Consider, for example, a physics student who refuses to internalize and apply proper rules for solving differential equations. If we conclude, as we are likely to do, that such a student is not exercising a mature independence of mind but is instead displaying a stubborn refusal to learn, it is because the discipline of physics understands these aspects of mathematics to be dogmatic in character. Contrast this physics student to an English undergraduate who refuses to agree with a professor's interpretation of Middlemarch. Whether such an undergraduate is thinking for him- or herself or instead is stubbornly refusing to learn must depend upon an appraisal of the quality of his or her own countervailing interpretation of Middlemarch, an appraisal that is virtually impossible without relevant disciplinary norms of literary criticism.

fellow students if they question politically correct ideas... What happens when the intellectual freedom of politically unfashionable colleagues or students is threatened by other professors, who are protected by tenure and 'departmental autonomy'? It is important to understand how dramatically the situation has changed. Professors who once preached objectivity now celebrate subjectivity. The measure is not truth but power-especially the power of one's race, class, and gender. The aim is not to educate the young to think for themselves but to transform them into 'change agents' for the professor's own brand of social engineering" (ibid.).

72. Students for Academic Freedom, "Mission and Strategy," www. studentsforacademicfreedom.org/essays/pamphlet.html. For a survey of recent legislative attempts to regulate classroom teaching, see www.aaup.org/AAUP/GR/ABOR/ legislationsummary.htm

73. University of California, Academic Personnel Manual, §o10, www.ucop.edu/acadadv/ acadpers/apm/apm-o10.pdf

74. See, for example, AAUP, Statement on the Academic Bill of Rights, www.aaup.org/ AAUP/comm/rep/A/abor.htm; "DP," pp. 298-99; and AAUP, "Joint Statement on Rights and Freedoms of Students," in AAUP, Policy Documents and Report, p. 262.

75. For a discussion, see Post, "The Structure of Academic Freedom," pp. 79-81. 
This implies that the distinction between education and indoctrination does not depend upon anything so simple as whether a student is required to learn or use specific information or facts or theories. The distinction follows instead from the application of relevant disciplinary standards, which define the objects and practices of knowledge that legitimate pedagogy aspires to inculcate. To the extent that humanities scholars repudiate such standards and purport to speak only as sage amateurs, to the extent that they do not purport to be communicating expert knowledge but only the views of alert citizens, they are rendered vulnerable to charges of indoctrination by students who may be offended by what they perceive to be heuristically irrelevant political bias. ${ }^{76}$ The question of whether humanities scholarship depends upon disciplinary or charismatic authority will thus have significant implications for the capacity of universities to maintain independence from external forces seeking to control the content of pedagogy in the humanities.

It has rightly been said that disciplines must be studied from both an "external" and an "internal" point of view. ${ }^{77}$ We have so far considered how disciplinary debates serve external and systemic functions by mediating between the university and its ambient environment. We have seen how disciplinary debates facilitate the ongoing adjustments necessary for universities to achieve their mission of producing knowledge and how they mark the boundaries of academic autonomy from extramural supervision. It is also important, however, to consider disciplinary debates from an internal perspective and to trace how they serve to articulate and enact professional solidarity and identity.

Successful disciplines do not merely come at faculty from the outside, as it were. Faculty typically serve long apprenticeships during which they are socialized into disciplinary practices. These practices are internalized and become a kind of "language" in which well-socialized graduate students learn to express their ambition to produce scholarship. ${ }^{7}$ In this way a discipline becomes a "discursive 'community"'79 in which participants converse with each other in a common language in the hope of recognition

76. This point needs to be framed delicately because academic freedom to teach does not protect only the inculcation of professional knowledge. (Academic freedom of research, by contrast, is justified primarily in terms of the creation of professional knowledge.) As a practical matter, however, the current political climate means that potentially offensive teaching that is not defensible as an effort to instill disciplinary knowledge will be exceedingly vulnerable to the charge of political indoctrination. For a full discussion of these complexities, see Finkin and Post, For the Common Good, pp. 79-111.

77. Fuller, "Disciplinary Boundaries and the Rhetoric of the Social Sciences," p. 302.

78. Lynn Hunt, "The Virtues of Disciplinarity," Eighteenth-Century Studies 28 (Autumn 1994): 2.

79. Rena Lederman, "Towards an Anthropology of Disciplinarity," Critical Matrix 15 (Summer 2004): 60 n. 3 . 
and persuasion. ${ }^{80}$ The regulative idea of disciplinary unity, which I mentioned earlier, refers to the possibility of this conversation, to the implicit presupposition that disciplinary work will be intelligible and relevant to an audience of peers who participate in the same discursive community. ${ }^{81}$

In all these respects a discipline constitutes a community of inquiry possessing the characteristics of what Alasdair MacIntyre has defined as a "practice," which is

any coherent and complex form of socially established cooperative human activity through which goods internal to that form of activity are realized in the course of trying to achieve those standards of excellence which are appropriate to, and partially definitive of, that form of activity, with the result that human powers to achieve excellence, and human conceptions of the ends and goods involved, are systematically extended. Tic-tac-toe is not an example of a practice in this sense, nor is throwing a football with skill; but the game of football is, and so is chess. Bricklaying is not a practice; architecture is. ${ }^{82}$

Disciplines are coherent and complex forms of human cooperation that contain standards of excellence. Those who master a discipline can experience what MacIntyre calls an "internal good," which is a form of satisfaction that can arise only from excelling within a practice. ${ }^{83}$ One cannot master a practice without training and an apprenticeship:

80. For an excellent recent account that studies disciplinarity in the context of institutions of peer review and that stresses "the importance of considering self and emotions_-in particular pleasure, saving face, and maintaining one's self-concept-as part of the investment that academics make in scholarly evaluation," see Michèle Lamont, How Professors Think: Inside the Curious World of Academic Judgment (Cambridge, Mass., 2009).

81. From the perspective of this conversation, it is indeed true that "disciplinary boundaries are necessary to ongoing research; otherwise one would not know where to begin, what to find, how to give evidence" (Jacqueline Henkel, "Defining Interdisciplinarity," PMLA 111 [Mar. 1996]: 279).

82. Alasdair MacIntyre, After Virtue: A Study in Moral Theory (Notre Dame, Ind., 1981), p. 175; hereafter abbreviated $A V$.

83. MacIntyre writes:

There are ... two kinds of good possibly to be gained by [the practice of] playing chess. On the one hand there are those goods externally and contingently attached to chess-playing and to other practices by the accidents of social circumstance ... such goods as prestige, status and money. There are always alternative ways for achieving such goods, and their achievement is never to be had only by engaging in some particular kind of practice. On the other hand there are the goods internal to the practice of chess which cannot be had in any way but by playing chess or some other game of that specific kind. We call them internal for two reasons: first, as I have already suggested, because we can only specify them in terms of chess or some other game of that specific kind and by means of examples from such games; ... and secondly because they can only be identified and recognized by the experience of 
A practice involves standards of excellence and obedience to rules.... To enter into a practice is to accept the authority of those standards and the inadequacy of my own performance as judged by them. It is to subject my own attitudes, choices, preferences and tastes to the standards which currently and partially define the practice.... The standards are not themselves immune from criticism, but none the less we cannot be initiated into a practice without accepting the authority of the best standards realized so far. If, on starting to listen to music, I do not accept my own incapacity to judge correctly, I will never learn to hear, let alone to appreciate, Bartok's last quartets. $[A V$, p. 177]

Once initiated into the practice of a discipline, scholars can differ about its standards and their application. Criticism and debate can sometimes become so vigorous that a discipline, like a "living tradition," can evolve into "an historically extended, socially embodied argument, and an argument precisely in part about the goods which constitute that tradition" ( $A V, \mathrm{p}$. 207). Yet, as long as participants continue to argue with each other in the name of a common discursive community, a discipline can retain its vigor and integrity. The community is in part held together by a shared pursuit of the internal good of excellence, by the sheer potential satisfaction of authoring first-rate literary criticism or an outstanding ethnography or an elegant mathematical paper. ${ }^{84}$

These are "pleasures" that can accrue only to those who have fully internalized the standards by which such success is measured..$^{85}$ The pleasure of excellence presupposes an ongoing commitment to the discursive community that is authorized to define and bestow the attribute of excellence. It is striking that scholars who attempt interdisciplinary work sometimes compare the experience to "learning a foreign language and experiencing a

participating in the practice in question. Those who lack the relevant experience are incompetent thereby as judges of internal goods. [AV, p. 176]

84. "The qualities that are considered desirable, and those that are to be avoided, vary from discipline to discipline. The terms commonly used for the purpose of approbation and disapprobation help to pinpoint disciplinary values and to mark the defining characteristics of any given field" (Becher, "Disciplinary Discourse," Studies in Higher Education 12, no. 3 [1987]: 263).

85. Ray P. Bowen, “A Return to the 'Disciplines,"” Modern Language Journal 26 (Feb. 1942): 101. An important dimension of the crisis of literary studies is no doubt captured by Clifford Siskin's offhand observation that "knowledge production today within the traditional disciplines is no longer experienced-following Wordsworth's and Mill's prescription-as inherently pleasurable" (Siskin, "Gender, Sublimity, Culture," p. 38). 
foreign culture," with the greatest benefit being that it "creates a different relationship to one's own discipline." 86

Disciplines change and develop for a great many reasons, but no doubt the most systematic pressure for change is the continuing need to satisfy the externally driven research agenda of universities. Universities support disciplines because they produce the kind of knowledge for which there is demand. The nature of this demand is continuously in flux, sometimes in abrupt and dramatic ways. If a discipline is to maintain its internal logic and coherence, it must mediate these demands through the filter of an established disciplinary culture. When the tension between external demands and internal culture becomes too great, a discipline can divide or disintegrate. The regular mitosis of scientific disciplines most likely reflects the rapidly changing rate of external demands that the sciences (particularly the applied sciences) must satisfy.

As scholars within a discipline negotiate the stress of satisfying new demands, they debate the question of disciplinarity. We have seen that the stakes of such debates can be characterized instrumentally as a form of "opportunism in knowledge production." But our present discussion suggests that this characterization is incomplete. Disciplinary debates are always also about professional identity and solidarity. They are about the substantive nature of a disciplinary practice: the kind of discursive community scholars desire to inhabit; the kind of work that they find most meaningful and gratifying; the kind of colleagues they wish to recognize as peers; the forms of disciplinary language that are most suited to scholarly aspirations. These are deeply important and consequential matters, and they are all implicated in debates about the meaning of disciplinarity. In fact, I suspect that they are the fuel for the most intense and heated aspects of these debates.

Just as disciplines perform multiple functions, so debates about disciplinarity can vary in their stakes. They can be coldly instrumental, concerned with organizing knowledge practices so as to most efficiently solve salient research agendas. Or they can be passionately expressive, concerned with affirming the value and meaning of disciplinary work. It is important to carefully separate these two kinds of debates, for they differ fundamentally in character. Both occur regularly throughout the academy.

There is a third kind of debate, however, that seems primarily situated

86. Hunt, "The Virtues of Disciplinarity," p. 6. "Scholars," Wissoker writes, "turn out to have great affective attachments to the methods of their own fields, even if they spend much of their academic lives grumbling about them or picking them apart" (Wissoker, "Negotiating a Passage between Disciplinary Borders," p. B5). 
in the humanities. This debate concerns disciplinarity as such, and it focuses on the relative merits of charismatic and disciplinary authority. Although rarely framed in this way, it is a debate that fundamentally implicates the autonomy that universities may properly claim from the control of external forces. Academic freedom, which defines the sphere of the university as independent from such control, extends to the creation of professional knowledge, which is to say of disciplinary knowledge. It does not safeguard mere amateurs who wish to contribute to the political development of the nation. It would be well to have this consequence in mind as we seek to understand the concept of disciplinarity in the humanities. 


\section{Non-resistance}

aggressive, 142 as a misleading term, 4 


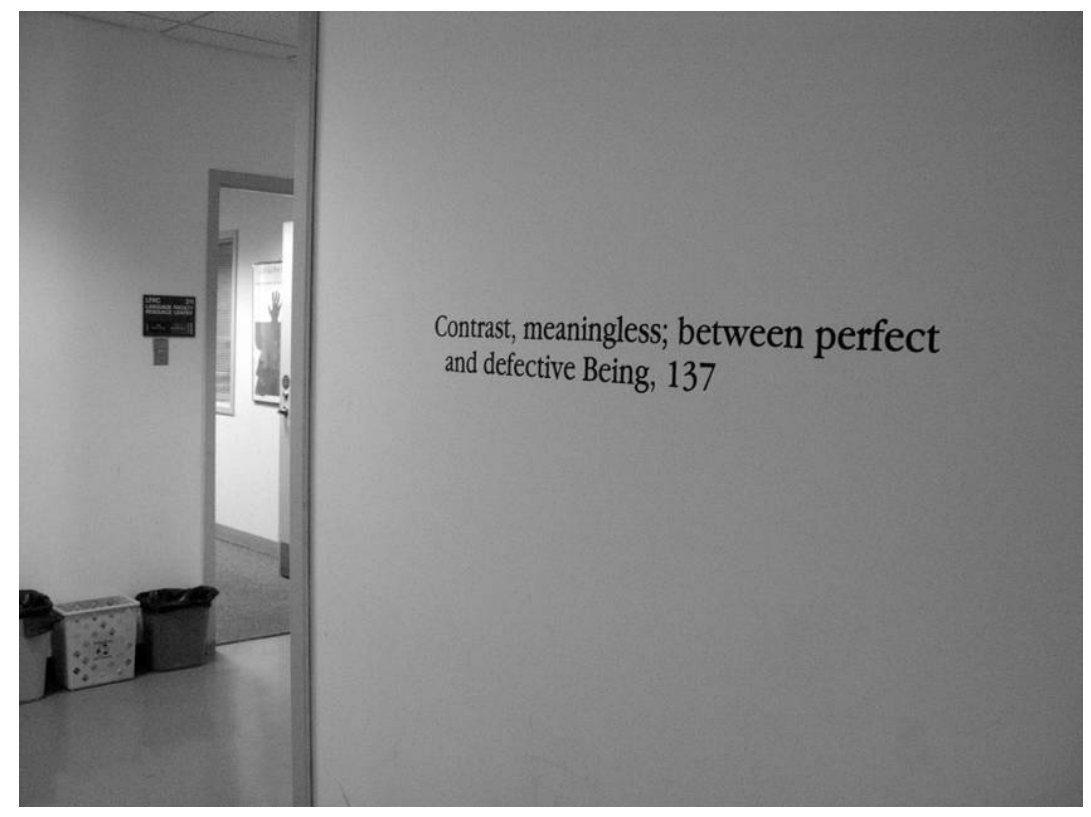

